\title{
SONHO, UM OBSERVATÓRIO PSÍQUICO: PSICOPATOLOGIA FUNDAMENTAL E SUBJETIVIDADE
}

\author{
Regina Maria Guisard Gromann e Manoel Tosta Berlinck
}

\author{
Regina Maria Guisard \\ Gromann \\ Psicóloga clínica, \\ psicanalista, mestre \\ em psicologia \\ clínica pela PUC-SP \\ Manoel Tosta Berlinck \\ Sociólogo, \\ psicanalista, Ph.D. \\ pela Cornell \\ University, \\ professor do Núcleo \\ de Psicanálise \\ do Programa de \\ Estudos Pós- \\ graduados em \\ Psicologia Clínica \\ da PUC-SP
}

RESUMO: Este artigo tem como objetivo situar o sonho na psicopatologia fundamental, a qual se estabelece na dimensão da subjetividade. O caráter onírico guarda em sua essência a condição de miragem e de observação dos fenômenos psíquicos que se encontram destacados no processo psicanalítico. Desta maneira, pensar no lugar do sonho torna-se a principal condição deste processo, em que o sujeito, ao mesmo tempo contempla os resgates e reencontros dos seus movimentos psíquicos, da mesma maneira que engendra um espaço propício a eles. Desta maneira, propõe-se debater os aspectos constituintes do estado depressivo e as nuances marcadas pela sua passagem, no setting psicanalítico. Assim, a manifestação onírica parece tornar-se um observatório destas passagens constituídas a partir de um sonho sonhado pela dupla analítica, que é transformado em história analítica.

Palavras-chave: Sonho, subjetividade, psicopatologia fundamental.

ABSTRACT: Dreams, a psychic observatory: fundamental psychopathology and subjectivity. This article aims at placing the dream in Fundamental Psychopathology, a field based on the dimension of subjectivity. In their essence, dreams are like mirage, and a means for observing the psychic phenomena that become relevant in the psychoanalytic process. Being attentive to dreams is a sine qua non condition for this process, in which the subject, as it contemplates aspects and encounters that are recurrent in its mental movements, opens up a space which is favorable for them. Our purpose here is to discuss the constitutive aspects of the depressive state and the nuances marked by its passage through the psychoanalytic setting. The manifestations of dreams become an observatory, as it were, of these passages constituted on the basis of a dream dreamed by the analytic pair, that is, converted into analytic history.

Keywords: Dream, subjectivity, fundamental psychopathology. 
Essas coisas assim a gente mesmo não pega, não abarca. Elas pertencem à luminosidade da noite.

Aragem do sagrado. Absolutas estrelas.

GUIMARÃES ROSA, 1986

A mente humana está fundamentalmente ligada à experiência e ao desejo.

ALBERT EINSTEIN, 2000

É

no jogo onírico do esconder e revelar que o subjetivo também se constrói. Determinado por seu caráter fugidio, o sonho é um fenômeno a ser decifrado - um enigma ambivalente e paradoxal que não se constitui para ser resolvido, mas para permanecer como uma possível dimensão do sujeito em busca de sua existência. Nesse sentido, o sonho é resultado de um jogo de forças psíquicas, em permanente tensão, tornando-se um observatório privilegiado, um campo de exame e verificação de acontecimentos em movimento ricos em descobertas. Como num observatório astronômico - quanto mais o ser humano põe-se a contemplar os corpos celestes e suas radiações, mais indaga-se acerca de sua própria realidade, numa relação dialética: distâncias e relações entre os planetas, os desenhos que perfazem, seus atritos e choques, desaparecimentos nos buracos negros, os surgimentos de novas constelações e os rastros de luz deixados pelas estrelas que, ao serem avistadas, sinalizam que não mais existem. De maneira análoga, o sonho como observatório psíquico remete aos fenômenos inapreensíveis, porém detectáveis, do universo da condição humana. É eterno em seu tempo. O enigma da esfinge em Édipo nos indica este rumo.

O homem em seu desamparo original possui como ponto de ancoragem a sabedoria advinda da vivência de seu sofrimento psíquico. O paradigma dessa vivência é o encontro com o outro, apresentando-se como um campo potencial, de onde surge o sonho, condição de manifestação do subjetivo que há em todos nós, o estranho.

Entretanto, qual seria o lugar do sonho na psicopatologia fundamental? Em primeiro lugar, é preciso dizer que a psicanálise estabelece a dimensão da subjetividade no âmago da psicopatologia, ou seja, leva em consideração não apenas uma descrição dos fatos, mas de como estes se articulam a partir do sujeito falante acerca de sua dor. Nas palavras de Berlinck (1998, p.57):

“A posição da psicopatologia fundamental é tal que se dispõe sempre a escutar um sujeito portando uma única voz que fale do pathos que é somático e que vem de longe e de fora, ela é sempre objeto da transferência, ou seja, de um discurso narrando o sofrimento, as paixões, a passividade vindo de longe e de fora e possuindo um corpo 
onde brota, para um interlocutor, por suposição, capaz de transformar, com o sujeito, essa narrativa numa experiência. Esta palavra adquire o sentido preciso de enriquecimento, ou seja, a experiência é a possibilidade de se pensar aquilo que ainda não foi pensado."

Ora, freqüentemente observamos no trabalho clínico o relato de pacientes procurando "objetivar" da melhor forma possível, sua dor, seja física ou psíquica, muitas vezes até constituindo nos primeiros encontros um relato dissociado dos acontecimentos de sua vida, na tentativa de organizar um discurso racional de suas dores; no entanto, no decorrer do trabalho terapêutico, o campo transferencial transforma-se: a qualidade do vínculo instaurado pela dupla analítica, e as produções emergentes através desta relação promove a já citada "transformação de narrativa em experiência”, relembrando suas vivências primordiais: "pensar o ainda não pensado".

Neste sentido, o sonho é manifestação paradigmática. O que de mais autêntico poderia aparecer para "contar" a história vivida na transferência? Assim, o fenômeno onírico seria uma das formas por excelência, de o sujeito informar seu sofrimento. O sonho seria, então, além da realização de um desejo, um verdadeiro observatório psíquico, um observatório astronômico, lugar de onde se avista as fugidias estrelas, "serviço de observações astronômicas ou meteorológicas" (FERREIRA, s/d.); em outras palavras, o sonho seria o lugar de avistar e examinar os fenômenos psíquicos, sendo esta capacidade uma condição aos poucos conquistada dentro da relação terapêutica, enquanto um campo potencial vai sendo criado na dupla. Sabemos que Freud utilizou-se dos sonhos tanto para ampliar a metapsicologia psicanalítica, quanto para realizar sua auto-análise, e, nesse sentido, colocou o fenômeno onírico no centro das investigações do psiquismo.

\section{PSICANÁLISE E PSICOPATOLOGIA FUNDAMENTAL. O LUGAR DO SONHO}

Assim, a herança deixada pelo citado trabalho de Freud é, até hoje, motivo de muitos estudos, inclusive este, baseado na suposição de que o campo do sonho poderia se constituir em lugar de descobertas, exames e reflexões; uma produção nascida da relação intersubjetiva, na transferência, capaz de ampliação do campo da consciência, da vida psíquica do sujeito, numa relação dialética. A concepção do sonho coloca a psicopatologia fundamental em sua posição mais autêntica pois, considerando o sujeito na sua singularidade, traz sua própria história inconsciente, revelando o que de mais próprio ela possui — sua subjetividade. Tornar-se sujeito de seu sofrimento significa envolver-se com a história daquilo que o faz sofrer. As noções de pathos, paixão e logos, discurso, sinalizam um caminho a ser percorrido. "A psicopatologia fundamental está interessada em suscitar uma experiência que seja compartilhada pelo sujeito”, afirma Berlinck (1998, p.57): 
"A descoberta do inconsciente freudiano como manifestação do pathos e como algo que surge da violência primordial, bem como a conseqüente metapsicologia que é conhecida por psicanálise é a casa confortável existente na contemporaneidade para a psicopatologia fundamental."

Fédida vai debater a necessidade crescente da delimitação metapsicológica freudiana para se compreender a psicopatologia. A “cientificidade em detrimento da psicanálise deve ser reconsiderada” e o autor concebe "uma perspectiva que define seu objeto indicando a posição do sujeito que observa: perspectiva do aparelho psíquico há muito anunciada e posteriormente definida em termos de ponto de vista” (FÉDIDA \& LACOSTE, 1998, p.23).

Ora, Freud, em $A$ interpretação dos sonhos (1900), apresenta um primeiro esboço metapsicológico de um lugar, um topos onde os processos oníricos se apresentavam, inaugurando a metapsicologia freudiana. Até então, diz Fédida:

“...a psicopatologia estava fundada num modelo descritivo da semiologia médica e da nosografia psiquiátrica. Conhece-se o debate inaugural de Freud com a semiologia e a nosografia de sua época - debate esquematicamente "controlado" pela questão da etiologia das neuroses, por um lado, e pelo problema das localizações cerebrais, por outro em um primeiro movimento, Freud desloca a concepção da psicopatologia, acrescentando-lhe a consideração não mais apenas dos sintomas de doenças repertoriadas, mas sinais da expressão do psíquico inseridos no funcionamento "normal" habitual e do qual a "doença” apenas reproduziria caricaturas ou aumentos." (FÉDIDA \& LACOSTE, 1998, p.25)

E mais adiante:

"Não tem mais fundamento negligenciar a idéia de que um jovem pesquisador, Freud, queria "dar seu nome a um território cerebral” (ou mesmo ligar seu nome, assim como seus predecessores, a um sintoma, à descoberta de uma substância, de uma técnica etc.) nem esquecer o explícito chamamento à transferência, formulado como uma advertência ao leitor, em $A$ interpretação dos sonhos." (Idem, p.26)

Assim, não é possível mais uma mera descrição etiológica do sintoma, apartado de um significado inconsciente, mas sim articulado na relação de transferência, possibilitando um terceiro lugar de observação para os fenômenos psíquicos em que o sonho seria o principal representante. É a posição do sujeito observador, e a perspectiva de um lugar de onde isto ocorre, o sentido relevante a ser considerado, e sua subseqüente relação do fenômeno com o observador aquilo que nos move ao conhecimento subjetivo. 
Assim, a noção de observatório é a possibilidade do surgimento de um terceiro olhar a partir da relação compartilhada, promovendo a condição de exame e investigação dos conflitos. A aquisição da qualidade do sujeito observar-se vai pouco a pouco sendo internalizada por ele e, ao narrar o sonho, constitui, ao mesmo tempo, sua história e costura seu psicossoma, rompido por traumatismos da vida de vigília, ganhando este terreno dimensão psíquica ao nomear a carne dolorida. Aquilo que não tinha ainda condições de ser pensado passa de relato mitológico a narrativa de experiência; o sonho vivido em imagens passa agora por outro processamento, como num moinho, passando de matéria-prima bruta a produto psíquico. Este campo, além de possuir como instrumento a interpretação, poderia ser, igualmente, lugar de construção. Assim, o sonho torna-se um mito eterno, lugar de construção e desconstrução.

Conceber as diferenças entre psicopatologia fundamental e psicopatologia geral leva-nos à questão da singularidade que repousa em cada sujeito; a noção de subjetivo, portanto, foi iniciada por Freud, que nos arremessou nesta odisséia, o inconsciente erotizado. No entanto, esta, como outras descobertas, foram marcadas por resistências. Do psiquismo humano faz parte o narcisismo, e um golpe nele pode levar a profundas resistências à verdade. A humanidade já passou por algumas delas, como a terra não ser o centro do universo e a descoberta de existir um estranho dentro de si mesmo, o inconsciente. Nesta medida, o alcance do sonho como método de aproximação com este estranho seria muito semelhante à experiência vivida pelos astrônomos da Idade Média, que se punham a descobrir corpos celestes colocando o homem cada vez mais descentralizado de sua onipotência.

\section{SONHO E DEPRESSÃO: UMA RELAÇÃO DIALÉTICA}

Sabe-se que o ser humano passa, invariavelmente, por períodos de reconstituição narcísica, advindas do próprio contato com o mundo, por vezes, inóspito.

“A depressão seria, então, um estado durando o tempo necessário para que o vazio
inanimado do vivo se constitua como organização narcísica e retorna toda vez que o
psiquismo solicita uma restauração de seu narcisismo. Como este está constantemen-
te ameaçado, tanto por forças externas como internas, a depressão está invariavel-
mente presente. O humano, como se sabe, não suporta por muito tempo o contato
com a dura realidade e um dos recursos à sua disposição para se proteger desse
contato tão frustrante e ameaçador é a depressão.” (BERLINCK \& FÉDIDA, 2000, p.15)

Por outro lado, um outro movimento começa a irromper após esta hibernação, chamado depressividade, brotações primaveris que inauguram o emergir da sensorialidade. "O sonho e a fantasia se fazem presentes, marcados por sentimentos, por afetos, as manifestações do erotismo fazendo parte da sensorialidade." 
(Idem, p.17). Em suma, há, assim, uma relação dialética entre a cavidade hibernal da depressão e o convexo da depressividade habitando o psiquismo humano. Como Bion nos diz em seus textos, há uma passagem constante entre posição esquizoparanóide e posição depressiva e vice-versa. A constituição do psiquismo estaria marcada inevitavelmente por essas passagens constantes (Ps-D, D-Ps), em que o sonho seria o indicativo e o observatório privilegiado para conter as imagens vividas das quais tornam-se, a cada vez, experiências "filmadas". A compreensão da realidade psíquica vai nos remetendo ao trabalho do sonho contendo em seu cerne a associação livre como marca de radiação de caminhos percorridos e lançando o sujeito em uma viagem mental, um flanar a partir de eventos a suscitar uma gama de intensidades psíquicas, as quais promovem uma geração de significados, criação.

\section{A POSIÇÃO DO SUJEITO QUE OBSERVA E PENSA VERSUS A POSIÇÃO DO SUJEITO QUE ESTÁ À MERCÊ DA ATIVIDADE FEBRIL E UTILITÁRIA DA MODERNIDADE}

O termo flâneur levar-nos-ia a essa imagem evocada; daquele sujeito que vive o mundo e o registra como um sonho "brotando" no momento de sua convalescença. Porém, esta experiência só ocorre na presença do outro. Sem esta condição estamos diante do devaneio estéril, um refúgio psíquico que, em vez de trazer à tona a dialética mantida pelo sonho, faz o sujeito mergulhar num ciclo estéril no qual o refúgio psíquico do devaneio e da onipotência é a única possibilidade de sobrevivência.

Desta maneira, a vida humana vista a partir do filtro do sonho conduz, paradoxalmente, à realidade do psiquismo e ao termo adotado por Baudelaire: o flâneur. Assim Hannah Arendt (1997, p.142-3) refere-se a este personagem do mundo moderno, ao biografar Walter Benjamin:

“É ao flâneur, vagueando sem rumo por entre a multidão das grandes cidades, em oposição deliberada à sua atividade febril e utilitária, que as coisas revelam o seu sentido íntimo (...), e só o flâneur, na sua errância descuidada, consegue captar a mensagem."

Essas palavras remetem ao sentido de apreensão do mundo por meio do fenômeno onírico, em oposição à operacionalidade estéril, sem vida, do mundo moderno, resgatando o simbólico e subjetivo do homem. É, pois, nesta “errância descuidada”, não obstante, temida por surpreender e espantar, que captamos aquilo de mais singular existente em todos nós, no encontro analítico. Seria esta condição que nos levaria ao conhecimento do surpreendente, desconhecido e estranho habitado em todos nós. E este observatório seria algo que constitui um terceiro olhar, levando sempre em conta aquilo que parece mais absurdo. 
A seguir, o flâneur de Baudelaire: Flâneur - 0 que observa $e$ o que sonha 0 mundo (BAUDELAIRE, 1995), apresenta imagem em seu artigo "O artista, homem do mundo, homem das multidões e criança”, produzindo um mergulho no universo onírico e suas características. Neste texto, o autor apresenta o flâneur, metáfora característica do espírito daquele que se põe a observar o mundo em movimento.

Ao traçar o perfil do pintor Constantin Guys, o autor retrata sua alma sempre pronta a conhecer o mundo com certa avidez.

"Comenta-se que Jean-Jacques Rousseau começou a escrever com 42 anos. Foi talvez por essa idade que C.G., obcecado por todas as imagens que lhe povoavam o cérebro, teve a audácia de espargir tinta e cores sobre uma folha branca. Para dizer a verdade, desenhava como um bárbaro, como uma criança, irritando-se contra a imperícia de seus dedos e a desobediência de seu instrumento." (BAUDELAIRE, 1995, p.855)

Conter todas as imagens excessivas e retratá-las num esboço, num continente, "espargindo" cores e formas dos afetos seria um dos intuitos do fenômeno onírico.

Por ser C.G. um apaixonado por viagens e correspondente de um jornal inglês ilustrado, publicava os seus croquis de viagem, em forma de pinturas, e dessa maneira transmitia suas impressões acerca delas. Não seria esta a maneira humana de comunicar acerca de suas viagens psíquicas?

Baudelaire segue traçando mais alguns aspectos da personalidade deste homem:

"Imagine-se um artista que estivesse sempre, espiritualmente, em estado de convalescença e se terá a chave do caráter de C.G. Ora, a convalescença é como uma volta à infância. O convalescente goza, no mais alto grau, como a criança, da faculdade de se interessar pelas coisas, mesmo por aquelas que aparentemente se mostram mais triviais. Retornemos, se possível, através de um esforço retrospectivo de imaginação, às mais jovens, às mais matinais de nossas impressões, e constataremos que elas possuem um singular parentesco com as impressões tão vivamente coloridas que recebemos ulteriormente, depois de uma doença, desde que esta tenha deixado puras e intactas nossas faculdades espirituais." (Idem, p.856)

O autor relaciona a convalescença de uma doença a este estado peculiar de apreensão sensorial do mundo, remetendo-nos ao despertar de alguém que sai de uma caverna hibernal, próprio da saída de estados depressivos, em que as primeiras brotações surgiriam após tempos de congelamento. Não estaríamos, então, referindo-nos aos primeiros sonhos depois de estados depressivos? O convalescente respiraria a vida após o congelamento invernal, espargindo cores e formas no mundo psíquico. 
Esta “infância redescoberta” seria, assim, o encontro com este mundo infantil soterrado e emergente através dos sonhos, sendo este momento um encontro com a sensorialidade: formas táteis, sedosas, “....as gradações de cores da pele matizada de rosa e amarelo, e a rede azulada das veias" (Idem). Paisagem, luz, brilhos, cores, o nascimento das imagens do sonho. E com estas palavras define o flâneur:

“A multidão é seu universo, como o ar é dos pássaros, como a água é dos peixes. Sua paixão e profissão é desposar a multidão.

Para o perfeito flâneur, para o observador apaixonado, é um imenso júbilo fixar residência no numeroso, ondulante, no movimento, no fugidio e no infinito. Estar fora de casa, e contudo sentir-se em casa onde quer que se encontre; ver o mundo, estar no centro do mundo e permanecer oculto ao mundo, eis alguns dos pequenos prazeres desses espíritos independentes, apaixonados, imparciais, que a linguagem não pode definir senão toscamente. (...) O amador da vida faz do mundo a sua família, tal como o amador do belo sexo compõe sua família com todas as belezas encontradas, encontráveis ou inencontráveis; tal como o amador de quadros vive numa sociedade encantada de sonhos pintados numa tela." (Idem, p.857)

Flâneur, portanto, poderia ser entendido como o estado de espírito de quem sai de uma depressão rumo à depressividade?

As imagens utilizadas para definir o espírito do flâneur é carregada de afeto e movimento, como num "caleidoscópio dotado de consciência”, parecendo atribuir a este estado um sujeito com sua reserva libidinal a caminho das relações com o mundo, com o objeto. “É um eu insaciável do não-eu, que a cada instante o revela e o exprime em imagens mais vivas do que a própria vida, sempre instável e fugidia” (Idem). Situar o sonho dentro da psicopatologia fundamental seria alinhá-lo a este momento do sujeito, o flâneur enquanto aquele que sai da lentificação de movimentos e do amortecimento da sensorialidade; em "convalescença”, para a captação do movimento das formas e cores sensoriais, na possibilidade do prenúncio da capacidade simbólica da qual o sonho é a gênese.

A reconstituição do psiquismo que passa por uma ruptura intensa, demarca o surgimento do simbólico no homem, constituindo sua subjetividade. Baudelaire nos convida a abstrair tudo aquilo que parece concreto e realístico, para vagarmos com ele no mundo da imaginação, e colocarmo-nos em contato íntimo com aquilo que procuramos apreender: algo tão fugidio como o fenômeno onírico.

A transformação das vivências sensoriais para a experiência do vivido se mantém, portanto, numa relação dialética entre o infantil e o adulto que vive em todo ser humano. Considerar este paradoxo parece ser função do trabalho do sonho.

Em suma, como afirmam BERLINCK \& FÉDIDA (2000, p.15): 
“.... depressão é, assim, um estado de vazio, de ausência, correspondendo a um tempo parado expondo o lugar e espaço, o fundo em relação ao qual ecoa o tempo da psique e permitindo dizer que ela define-se por uma posição econômica que concerne a uma organização narcísica do vazio segundo uma determinação própria para a inalterabilidade tópica da psique.”

Invocando ao sujeito uma caverna placentária capaz de promover um trânsito à depressividade. A alternância entre os dois estados depressão / depressividade é a dialética da permanente construção do psíquico. As vivências sensoriais explicitadas antes obrigam o homem a uma passagem: o encontro com a reflexão e o pensamento, transformando, assim, imagens sensoriais em experiência, em atributo histórico de sua vida. Deve passar por uma transformação. Da mesma maneira que a imagem do sonho, conteúdo manifesto, deve passar a pensamento onírico latente, e vice-versa.

\section{A CAPACIDADE DE PENSAR E TRANSFORMAR. O SONHO SONHADO PELA DUPLA ANALİTICA E TRANSFORMADO EM HISTÓRIA ANALÍTICA}

O que seria transformar o vivido sensorial mencionado em pensamento e história?

É necessário voltar às palavras de Berlinck, no início deste trabalho, quando ele menciona que a condição do sujeito e sua subjetividade se dão numa relação entre esse sujeito e um interlocutor, possibilitando, na escuta da transferência, transformar com ele uma narrativa em experiência - a experiência de se pensar aquilo que ainda não foi pensado. O sonho seria o lugar desse encontro e dessa transformação: transformar sofrimento em narrativa.

Sabemos, entretanto, que um sonho só se constitui à medida que é lembrado pelo sujeito e relatado a alguém. Esse processo surge, portanto, na experiência compartilhada da relação analítica, a qual torna-se o endereço apropriado para as transformações ocorrerem. O paciente parece intuir que aquele espaço constitui-se um lugar passível de mudanças, que até então não lhe aconteceram, ganhando sentido. Fédida afirma:

“...o que a análise permite reconstruir — através das expressões atuais da depressão — é o lugar que designa um vazio nessa relação: esse vazio é aquele que se instala entre um olhar e o rosto que não responde, entre um corpo de bebê e o gesto materno pensando em outra coisa, de alguma forma ausente, entre si e o outro que permanece fechado ou só devolve uma imagem enganosa - uma imagem na qual o bebê não se reconhece. O vazio vem no lugar desse inter que prefixa a subjetividade.” (FÉDIDA, 1999, p.99)

Poder-se-ia pensar, portanto, que a constituição desse vazio permite um espaço que até então não se configurou para o sujeito. 
“Mas, principalmente, é da descoberta (ou construção) do vazio como espaço 'entre’ que provém para o analista e o paciente uma percepção comum do intervalo necessário entre dois corpos para a fala e sua escuta." (Idem)

Transformar vazio em espaço potencial passível de troca: "Tudo o que acontece e, sobretudo, que se fala entre uma mãe e seu filho é esse tempo: o vazio aí é o espaço" (Idem). Constitui-se a partir desta reconstrução, em primeiro lugar, um espaço, antes congelado em vazio pela ausência da mãe e impossibilitado de mover-se em espaço potencial de trocas entre paciente e analista. Em segundo lugar, as brotações oníricas: o sonho, nessa medida, seria o observatório comum para a dupla analítica nessa troca, um idioma configurando-se pouco a pouco na linguagem da relação. O sonho do vazio que não foi possível mover-se, congelado ao longo da vida do paciente.

Nesse sentido, é possível retomar a noção de subjetividade em Ogden, quando sua conquista seria a capacidade de o sujeito adquirir graus sucessivos de autopercepção, transitando desde uma auto-reflexão intencional até um sutil senso de autonomia, bem como a capacidade de qualificar seus sentimentos e pensá-los em oposição a um estado de reatividade reflexiva. Essa condição está explícita naquilo que Freud mencionou no item (B) do capítulo VII, “Regressão”, em A interpretação dos sonhos (1900/1987, p.489) “...e cabe assinalar o lugar dos sonhos na concatenação da vida anímica”. Esse lugar é onde a cena das vivências e dos conflitos ocorrerão, em oposição à reatividade reflexomotora.

Percebe-se, portanto, como esta conquista paulatina de autopercepção vai ganhando corpo, de acordo com os inícios de cada sujeito. A noção de sonho é aqui mencionada, pois caracteriza este observatório surgindo da relação dialética entre dois sujeitos descentrados. Esta descentralização é fruto dos três golpes narcísicos vividos pelo homem: a descoberta copernicana de que a terra não era o centro do universo, a descoberta darwiniana colocando o homem mesma escala que o animal, e, por último, a descoberta do inconsciente, “...descentrando o humano de si mesmo, solapando a ilusão da identidade entre a consciência e mente" (OGDEN, 1996, p.14). No entanto, é justamente este descentramento que levará o humano ao encontro de sua subjetividade.

É, portanto, o emergente destas duas subjetividades descentradas, num espaço potencial, o que engendrará a relação dialética criativa e o universo onírico.

Ogden assinala que

“...a subjetividade está relacionada à consciência, mas não é a mesma coisa que esta. A experiência da consciência (e da inconsciência) decorre da conquista da subjetividade. Esta é um reflexo da diferenciação de símbolo, simbolizado e sujeito interpretador. O surgimento de um sujeito no curso desta diferenciação torna possível a uma 
pessoa desejar. O desejo de fazer-se não percebedor de um aspecto do próprio sistema de significados prepara o palco para a diferenciação dos reinos consciente e inconsciente de experiência." (OGDEN 1995, p.82)

Ora, então poder-se-ia dizer que o campo do sonho, com seu revelar e esconder onírico, é a possibilidade de tal relação dialética iniciar-se. Estranho e familiar vão se compondo numa rede possível de conhecimentos superpostos, estabelecendo integrações e transformações no seio do sujeito. Enquanto a diferença não se estabelece nos inícios, não pode haver significado. Esta passagem entre um campo homogêneo na relação inicial, prepara o indivíduo para sua separação.

“A ‘singularidade' é tornada possível pela outra pessoa. Winnicott (1967b) descreve isto como sendo a descoberta, pelo bebê, de si próprio no que ele vê refletido nos olhos da mãe. Isto constitui uma dialética interpessoal na qual a individualidade e a alteridade criam-se mutuamente e são preservadas uma pela outra. A mãe cria o bebê e o bebê cria a mãe." (OGDEN 1995, p 82)

Ora, criar o mundo é a primeira condição de subjetividade. O objeto é inicialmente inventado pelo sujeito, sonhado por ele para depois ser objetivamente percebido. Neste sentido, o sonho é a película que envolve os acontecimentos brutos do mundo exterior; porém, da mesma maneira como o novo pode se tornar familiar por meio do sonho, há marcas de estranheza tatuadas nesta película, sustentando o revelar e o esconder do enigma humano. Essa película cria, assim, um campo formador de sonhos e significados, engendrando um espaço continente e guardião do desejo humano. Desta forma, o sujeito não ficaria à mercê da descarga de seus jorros pulsionais, mas com condições de conter seus desejos e pensá-los.

A partir dessas digressões, é necessário realizar uma distinção, pois este trabalho leva a pensar num ponto de observação: o observatório e o movimento do flâneur. É necessário distinguir, portanto, o processo de sonhar e o espaço onírico, onde se dá o sonho; um continente e um contido.

Gromann (2002) argumenta a respeito de uma pele psíquica servindo de primeira superfície às impressões do sujeito. E esta constituição conformar-se-ia no contato com o ambiente e nas primeiras relações maternas. Assim, a pele serviria de tela, constituir-se-ia no espaço potencial.

\section{O OBSERVATÓRIO (PONTO FIXO) E O FLANAR (MOVIMENTO): DOIS PONTOS DE VISTA PARA UM MESMO FENÔMENO}

Observatório é um lugar de observação, funda-se a partir da organização narcísica do vazio e ganha corpo por meio do movimento do flâneur. Que observatório é esse? 
Para a fenomenologia, o momento de surgimento de um sonho marca um novo campo denominado observatório psíquico; no entanto, embora essa imagem traga certa fixidez à compreensão, a instalação desse campo é um lugar de observar movimentos nascentes: um primeiro momento de captação do fenômeno, e depois de observação do fenômeno que foi captado. Dessa maneira, o observatório se funda como campo de reconhecimento de uma tensão, ou seja, um campo marcado por acontecimentos psíquicos. Quando o sujeito sonha pela primeira vez na análise, traz consigo essa demarcação. Até então era o vazio, organização narcísica do vazio.

Ao procurar a psicanalista, Nina julgava relevante contar acerca de sua vida, de seus sintomas; estava às voltas com sua própria gravidez, e foi após o nascimento de seu filho, e em meio às vivências pós-parto, que pôde trazer um sonho emblemático. Esse momento inaugural demarcou para a dupla um lugar, um topos, um observatório possível de miragem da tensão conflitual, no qual se via imersa: a vivência do parto e do nascimento remete-a a um tempo perdido de lembranças que começa a se precipitar. As brotações dessas lembranças surgem, configurando paralelamente um lugar de observação - um observatório psíquico privilegiado para mirar esses movimentos. Talvez aí o surgimento da sonda espacial como instrumento de captação. Este sonho emblemático funcionaria como epígrafe e tema principal das tensões conflituais que vinha vivendo.

Eis o relato do sonho:

"Meu marido está dirigindo uma motocicleta, com o nosso filho na garupa, um menino de 4 anos. Observo os dois caindo num grande buraco. São socorridos e levados para um hospital. Cheguei nesse estabelecimento e observei meu marido saindo pela porta de entrada; olho para ele e percebo, pelo seu olhar, que algo muito ruim acontecera com nosso filho. Adentro o hospital, desesperada, passando por várias portas internas e não o encontro. Até que, ao entrar na última, vi meu filho deitado em uma maca. Avisto uma nuvem sobre ele, da qual caíam gotas, como uma chuva. Olho e penso o quanto era estranho, pois estávamos em um local fechado. Percebo que estava vivo, e todos proferiam a palavra 'milagre'."

Ao relatar este sonho, Nina demonstrou estar angustiada, não por associá-lo com algo específico, mas pelo medo de que algo acontecesse ao filho.

Esse sonho parece condensar vários aspectos até então dispersos na vida de vigília da paciente, impossibilitando a reflexão. Tal dispersão era vivida por meio de atuações, sensações. Um bom exemplo disso era a "nuvem negra que a perseguia”, a sensação de morte emitida a todo momento, mesmo quando sua vida cotidiana transcorria da melhor forma possível (era casada "com um bom homem, tinha filhos perfeitos, conseguira se formar, comprara a casa própria” etc.). No entanto, pairava nela esse fantasma impossível de ser condensado numa cena que permitisse "visualizar" como num sonho, ou num observatório, os aspectos 
que achava tão estranho e inacessíveis à compreensão e à elaboração. Nesse sentido, pode-se pensar esse fantasma em termos de representação-coisa, algo como uma sensação que não se tornara uma representação de palavra, ou seja, ainda inacessível na cadeia associativa. Quando ela pôde sonhar esse sonho, alguns aspectos começaram a ser percebidos por ela, pois estavam condensados numa cena, como num take de filme. Em suma, o sonho catalisa essas imagens pulverizadas ao longo da vida do sujeito em forma de atuações que necessitam ser reunidas em imagens para serem pensadas; em outras palavras, um lugar de observação para reflexão.

Até o sonho emblemático referido antes, Nina não tinha se apoderado de sua psique e de seu espaço onírico como um instrumento de reflexão e transformação internos. Até então “contava” sua vida, mas dela não se apoderava de fato. Era perseguida por uma nuvem negra, repetindo uma sina. Após a sua gestação (biológica e analítica), inicia um tempo de apropriação de sua vida psíquica, inaugurando um espaço psíquico (observatório) e um processo onírico iniciado com o sonho emblemático e a encenação onírica. Após um congelamento para gestar o observatório, o processo de flanar teve início.

Em suma, o espaço onírico (observatório) e o processo de sonhar (flanar) são aquisições que surgem no decorrer do tempo analítico, propiciando um novo recomeço da vida psíquica, podendo ser reassumida como um destino, e não apenas uma sina repetitiva, sem sentido.

Uma das mudanças importantes ocorridas em Nina, após ter tido seu sonho inaugural, foi o início de uma fase em que podia realizar ligações relevantes entre a morte de sua mãe e sua depressão e descolar-se de um prolongado luto confundido com o vivido por sua avó — “ "nunca satisfeita”.

A questão da culpa e da sexualidade começaram a surgir com bastante força, bem como a possibilidade de possuir uma família. Poder usufruir de seu espaço, representado num primeiro momento por uma grande reforma realizada em sua casa - paredes foram quebradas, espaços foram remanejados, movimentos novos foram resgatados, sem perceber que essas mudanças poderiam colocá-la em risco.

O vislumbre do primeiro sonho nunca mais foi esquecido, e era usado freqüentemente nas sessões — o "milagre” de ter sobrevivido — a saída do buraco — novas portas se abrindo e o encontro com ela mesma se inaugurava - a viagem para a casa da avó no momento da reforma como início de um novo encontro com esse passado. Há um vaguear, um flanar por seu tempo, pela casa materna que antes estava impossibilitado pelo congelamento depressivo em que se encontrava. Não necessitava mais, segundo suas próprias palavras, “apagar seu passado”, mas podia "amarrar-se aos panos" e aos fios que ficavam soltos no decorrer de sua vida. 


\section{REFERÊNCIASS}

ARENDT, H. (1955-1968/1997) Homens em tempos sombrios. São Paulo: Companhia das Letras. (Foi utilizada, aqui, a tradução obtida pela Internet.)

BAUDELAIRE, C. (1863/1995) Poesia e prosa. Rio de Janeiro: Nova Aguilar. BERLINCK, M. T. (1998) O que é psicopatologia fundamental. Revista Latinoamericana de psicopatologia fundamental, v. I, n. 1, p.46-59-, mar. e FÉDIDA, P. (2000) A clínica da depressão: questões atuais. Revista Latinoamericana de psicopatologia fundamental, v. III, n. 2, p.9-25, jun/ 2000.

EINSTEIN, A. (2000) Como vejo o mundo. 24. ed. Rio de Janeiro: Nova Fronteira.

FÉDIDA, P. (1999) Depressão. São Paulo: Escuta, 1999.

. e LACOSTE, P. (1998) Psicopatologia/metapsicologia: a fun-

ção dos pontos de vista. Revista Latinoamericana de psicopatologia fundamental, v. I, n. 2, p.23-58, jun.

FERREIRA, A. B. H. (s/d) Dicionário Aurélio Eletrônico. v. 1.4. Rio de Janeiro: Nova Fronteira.

FREUD, S. (1900/1987) “A interpretação dos sonhos”. ESB. Rio de Janeiro: Imago.

GROMANN, R. M. G. (2002) "Corpo e subjetividade: a função do sonho na evolução psíquica”. Dissertação de mestrado em Psicologia Clínica. PUC-SP.

OGDEN, T. H. (1995) "Sobre o espaço potencial”, in GIOVACHINI, P. L. Táticas e técnicas psicanalíticas: D.W. Winnicott. Porto Alegre: Artes Médicas.

OGDEN, T. H. (1994/1996) Os sujeitos da psicanálise. São Paulo: Casa do Psicólogo.

ROSA, J. G. (1986) Grande sertão: veredas. Rio de Janeiro: Nova Fronteira, 1986.

Regina Maria Guisard Gromann

Av. Brigadeiro Faria Lima, 2121 conjunto 33

São Paulo SP

Tel (11) 3816-6845

rgromann@dglnet.com.br

Manoel Tosta Berlinck

Rua Tupi, 397/103

01233-001 São Paulo SP

Telefax (11) 3661-6519

mtberlin@uol.com.br 